\title{
Adiponitrile-based Electrolytes for High Voltage, Graphite-based Li-ion \\ Battery
}

\author{
Niloofar Ehteshami ${ }^{1}$, Aitor Eguia-Barrio ${ }^{2}$, Iratxe de Meatza ${ }^{2}$, Willy Porcher ${ }^{3}$, Elie Paillard ${ }^{\text {* }}$ \\ ${ }^{1}$ Helmholtz Institute Münster - Forschungszentrum Jülich (IEK-12), Correnstrasse 80, 48149 Münster, Germany \\ ${ }^{2}$ IK4-CIDETEC, Parque Tecnológico de San Sebastián, Paseo Miramon 196, 20014, Donostia-San Sebastian, \\ Spain
}

${ }^{3}$ CEA-LITEN, 17 avenue des Martyrs, 38000 GRENOBLE, France

\begin{abstract}
Operating high voltage lithium-ion batteries (LIB) is still an obstacle due to the limited anodic stability of state-of-the-art alkyl carbonates-based electrolytes which incorporate ethylene carbonate (EC). Thus, we replace here the widely used ethylene carbonate (EC)/dimethyl carbonate (DMC) solvent formulation by adiponitrile $(\mathrm{ADN}) / \mathrm{DMC}(1 / 1, \mathrm{wt} . / \mathrm{wt}$.$) , to enable room temperature electrolyte$ formulations with high anodic stabilities. The possibility of operating graphite with 1 M LiDFOB \& 1 M LiFSI ADN/DMC (1/1, wt./wt.) without additive is evidenced, with a clear advantage for the LiDFOB electrolyte. The addition of fluoroethylene carbonate (FEC) as a SEI additive results in improved graphite electrode performance in both cases and, less expectedly, in improved anodic stabilities.

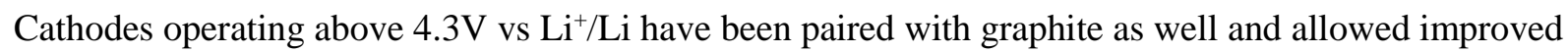
rate capability as compared to graphite half-cells. The safety of the electrolytes versus a charged graphite anode is improved as compared with state-of-the-art, EC-based electrolytes.
\end{abstract}

Keywords: Adiponitrile, graphite, additive, LiFSI, LiDFOB, Lithium-ion

\footnotetext{
* Corresponding author: e.paillard@fz-juelich.de
} 


\section{Introduction}

Li-ion batteries are a key technology for powering electric vehicles (EV) and increasing the EV driving range requires either increasing the capacity of the battery or its operating voltage (i.e. that of the cathode). However, conventional alkyl carbonates-based electrolytes decompose at high voltage, which limits the utilization of high voltage cathodes be them $\mathrm{LiNi}_{0.33} \mathrm{Mn}_{0.33} \mathrm{Co}_{0.33} \mathrm{O}_{2}(\mathrm{NMC})$ above 4.3V [1], or $\mathrm{LiMn}_{1.5} \mathrm{Ni}_{0.5} \mathrm{O}_{4}$ (LMNO) up to $4.8 \mathrm{~V}-5.0 \mathrm{~V}$ [2]. In order to enable high voltage Li-ion batteries, several alternative electrolytes with high anodic stability such as alkyl-sulfone [3], ionic liquids [4], or fluorinated alkylcarbonates [5] have been proposed. Among the alternative electrolytes, aliphatic alkyl dinitrile $\left(\mathrm{CN}\left(\mathrm{CH}_{2}\right)_{n} \mathrm{CN}, \mathrm{n}=3-8\right)$, such as adiponitrile ( $\left.\mathrm{ADN}, \mathrm{n}=4\right)$, offers among the highest anodic stabilities [6,7]. Besides, although $\mathrm{ADN}$ has a higher viscosity than $\mathrm{EC}\left(6.10 \mathrm{cP}\right.$ at $20^{\circ} \mathrm{C}$ vs $2.56 \mathrm{cP}$ at $25^{\circ} \mathrm{C}$ ) and a lower dielectric constant of $30\left(\right.$ at $\left.25^{\circ} \mathrm{C}\right)$ vs 89 (at $\left.40^{\circ} \mathrm{C}\right)[7,8]$, its high boiling and flash points surpass those of alkyl carbonate solvents [6].

In most cases, the utilization of graphite-based anodes is required for the preparation of high-discharge voltage cells. However, the operation of graphite anode in ADN-based electrolytes is problematic, due to their low cathodic stability and, most importantly for graphite operation, their poor ability to form a protective layer able to prevent extensive electrolyte decomposition and graphite exfoliation (the socalled Solid Electrolyte Interphase (SEI) $[9,10]$ ) during the first charge, unless ethylene carbonate (EC) is used as a co-solvent. In particular, Abu-Lebdeh et al. cycled graphite electrodes and graphite/ $\mathrm{LiCoO}_{2}$ cells in 1M lithium bis(trifluoromethansulfonyl)imide (LiTFSI) ADN:EC (1/1), with 0.1 M lithium difluoro(oxalate)borate ( $\mathrm{LiBOB}$ ) as additive to allow the formation of a stable SEI at the surface of the anode [6]. Some research was also conducted on the use of alkyl dinitrile as additives in conventional electrolytes, and some success have been reported concerning the operation of high voltage cathodes $[11,12]$, or safety and performance improvements of regular Li-ion cells at elevated temperature $[13,14]$, which are attributed to the adsorption of akyl dinitrile molecules at the cathode/electrolyte interface.

On the other hand, efforts have been directed toward EC free electrolytes, since EC is considered responsible for the failure of electrolytes at high voltage [1]. Gmitter et al. [15], in particular, reported the cycling of $\mathrm{MCMB} / \mathrm{LiCoO}_{2}$ cells, using VC or FEC as additives, for SEI formation and $\mathrm{LiBF}_{4}$ as a 
co-salt for preventing $\mathrm{Al}$ current collector corrosion using a LiTFSI/ADN-based electrolyte. Nevertheless, mesoporous carbon microbeads (MCMB) are known for allowing the use of PC-based electrolytes, which are typically incompatible with graphite [16]. The most recent report demonstrates the operation of $\mathrm{Li}_{4} \mathrm{Ti}_{5} \mathrm{O}_{12}(\mathrm{LTO}) / \mathrm{NMC}$ cells cycled in an ADN-LiTFSI electrolyte [17], however LTO is only a good material for lower energy application [18]. Thus, the possibility of operating graphite anodes with ADN-based, EC-free electrolytes had not been evidenced up to now.

In fact, the low solubility of typical inorganic salts such as $\mathrm{LiPF}_{6}$ and $\mathrm{LiBF}_{4}$ in pure alkyl dinitriles initially led toward the use of LiTFSI, a salt with high thermal and electrochemical stability and low lattice energy but which, as single salt, possesses poor SEI forming ability and induces Al current collector corrosion [7]. However, other salts, such as lithium difluoro(oxalate)borate (LiDFOB) and lithium bis(fluorosulfonyl)imide (LiFSI) are good candidates for substituting $\mathrm{LiPF}_{6}$ as they provide enhanced SEI forming ability in various type of electrolytes [19-21]. In addition, they are usually more soluble in organic aprotic solvents, including those with lower dissociating properties than typical EC mixtures. Thus, in this work, we report on the electrochemical performance of EC-free electrolytes based on ADN/DMC(1/1, wt./wt.) electrolytes with $\mathrm{LiPF}_{6}, \mathrm{LiDFOB}$ or LiFSI, either alone or combined with fluoroethylene carbonate (FEC) as additive for a use in high energy, graphite-based Li-ion cells.

\section{Experimental}

\section{Electrolyte preparation}

The electrolytes were prepared by adding appropriate amounts of lithium salts, either as received $\left(\mathrm{LiPF}_{6}\right.$ (BASF, Selectilyte $\left.{ }^{\mathrm{TM}}, 99.99 \%\right)$ ) or dried under vacuum for $48 \mathrm{~h}$ at $80^{\circ} \mathrm{C}$ (LiDFOB (Aldrich)), or $90^{\circ} \mathrm{C}$ (LiFSI (99\%, PROVISCO CZ)) to the solvent mixtures. Dimethyl carbonate (DMC) and fluoroethylene carbonate (FEC) (BASF, Selectilyte ${ }^{\mathrm{TM}}$ ) were used as received. ADN (Aldrich, 99\%) was distilled under vacuum and dried on molecular sieves at room temperature until the water content dropped below 20 ppm as determined by coulometric Karl-Fischer titration (KF 851 Titrando, Mettler Toledo). Electrolyte preparation was conducted in a MBraun glove box filled with $\operatorname{argon}\left(<1 \mathrm{ppm} \mathrm{H}_{2} \mathrm{O} \& \mathrm{O}_{2}\right)$.

\section{Electrodes}


Graphite electrode (96/2/2 (graphite (SLP30, Timcal)/CMC/SBR)) of $7.5 \mathrm{mg} \mathrm{cm}^{-2}$ active material loading were utilized in half-cells. $\mathrm{LiFe}_{0.37} \mathrm{Mn}_{0.63} \mathrm{PO}_{4}$ (LFMP) electrodes ( 89 wt.\% active mass loading and $2.3 \mathrm{mAh} \mathrm{cm}^{-2}$ ) and graphite electrode of $95 \mathrm{wt} . \%$ active mass loading and $2.65 \mathrm{mAh} \mathrm{cm}^{-2}$ (both anode and cathode with water-based formulations) have been used in full-cells. $\mathrm{LiNi}_{0.33} \mathrm{Mn}_{0.33} \mathrm{Co}_{0.33} \mathrm{O}_{2}$ electrodes of 86 wt.\% active mass loading and $2.0 \mathrm{mAh} \mathrm{cm}$ (when charged at $4.3 \mathrm{~V} \mathrm{vs}^{-2} / \mathrm{Li}^{2}$ ) were pressed at $3 \mathrm{t} \mathrm{cm}^{-2}$ and paired with graphite electrodes of $96 \mathrm{wt} . \%$ active mass loading and $2.2 \mathrm{mAh} \mathrm{\textrm {cm } ^ { - }}$ ${ }^{2}$ (both purchased from Custom Cells (Germany)).

\section{Electrochemical testing}

Electrochemical investigations were performed with 3 electrode Swagelok ${ }^{\mathrm{TM}}$ cells with Li counter and reference electrodes (Rockwood lithium) using a stack of 6 layers of Freudenberg FS2026 non-woven poylpropylene separator drenched with $200 \mu \mathrm{l}$ of electrolyte. The cells were assembled in an argon filled MBraun glove box with $\mathrm{O}_{2}$ and $\mathrm{H}_{2} \mathrm{O}$ levels below $1 \mathrm{ppm}$. The electrochemical stability of the electrolytes was investigated by voltamperometry with a VMP3 potentiostat (Bio-logic). Cycling of half-cells and graphite/NMC full cells was carried out in a temperature-controlled chamber at $20^{\circ} \mathrm{C}$ using a Maccor 4300 battery cycler. Graphite/LFMP coin cells (CR2025, Hohsen) were assembled in a dry room $\left(-50^{\circ} \mathrm{C}\right.$ dew point) using $75 \mu 1$ of electrolyte. The electrodes were separated by a layer of polyolefin separator (Celgard 2325, trilayer PP/PE/PP, $25 \mu \mathrm{m}$-thick). The cell performance was evaluated using a BaSyTec CTS multichannel cell test system in temperature-controlled room at $25 \pm 1^{\circ} \mathrm{C}$. Conductivity measurements were performed using a BioLogic MCS10, impedance-based conductimeter between $60^{\circ} \mathrm{C}$ and $25^{\circ} \mathrm{C}$ by $5^{\circ} \mathrm{C}$ increments spaced by 20 minutes ramps.

\section{Thermal analysis}

Differential scanning calorimetry (DSC) was used to follow the thermal events occurring during a heating ramp, with the electrolytes in contact with charged graphite anodes with a DSC Q2000 (TA Instrument) under He flow. The high pressure capsules were sealed in an argon filled glove box with $\mathrm{H}_{2} \mathrm{O}$ and $\mathrm{O}_{2}$ content below $1 \mathrm{ppm}$. The samples were ramped at $10^{\circ} \mathrm{C} \min ^{-1}$ from $40^{\circ} \mathrm{C}$ to $300^{\circ} \mathrm{C}$. 


\section{Results and discussion}

\section{Physico-chemical properties of the electrolytes}

Fig.1a shows the conductivity of $1 \mathrm{M}$ Li salts solutions in ADN/DMC (1/1, wt./wt.). It should be noted that, at room temperature, the $1 \mathrm{M} \mathrm{LiPF}_{6} \mathrm{ADN} / \mathrm{DMC}$ electrolyte is not an homogeneous liquid, but a flowing whitish paste most likely including crystalline phase(s). Consequently, the conductivity curves show a large hysteresis between the cooling and heating ramps and do not exhibit a typical VogelTamman-Fulcher (VTF) behavior. In contrast, the other electrolytes exhibits a VTF behavior above their highest melting transition and the LiFSI electrolyte shows the highest conductivity with $5.8 \mathrm{mS} \mathrm{cm}^{-1}$ at $20^{\circ} \mathrm{C}$ whereas that of the LiDFOB electrolyte is $3.3 \mathrm{mS} \mathrm{cm}^{-1}$. In comparison, the conductivities of $1 \mathrm{M}$ LiTFSI EC/ADN (1/1, v/v.) is $3.6 \mathrm{mS} \mathrm{cm}^{-1}$ [22] and that of $1 \mathrm{M} \mathrm{LiBF}_{4}+0.1 \mathrm{M} \mathrm{LiBOB}$ is $\left.2.1 \mathrm{mS} \mathrm{cm}^{-1}\right)$ [7]. For LiFSI and LiDFOB, a first melting transition occurs within $\left[-25^{\circ} \mathrm{C},-20^{\circ} \mathrm{C}\right]$ and a small kink in the cooling ramp suggests the formation of a small fraction of crystalline phase around $\left[-5,-10^{\circ} \mathrm{C}\right]$ for the LiFSI electrolyte which, however, does not affect conductivity much.

For LiFSI and LiDFOB, the concentration was varied between 0.8 and $1.2 \mathrm{M}$ and different ADN/DMC ratios were tested at $1 \mathrm{M}$. The conductivities are shown in Fig.1b and Fig.1c. As can be seen, the conductivities are slightly higher at $1.2 \mathrm{M}$ while the conductivities at $0.8 \mathrm{M}$ are lower, which suggests that the salts are well dissociated in ADN/DMC 1/1, in accordance with the good conductivity of the electrolytes. Thus, the increase of the ADN fraction only results in conductivity loss, due to viscosity increase. A higher DMC content is beneficial in the case of 1M LiFSI. However, increasing the DMC ratio does not affect the conductivity of $1 \mathrm{M}$ LiDFOB electrolyte as a higher ionic association probably counterbalances the lowering of the viscosity in this case. It can be also observed that the addition of $2 \%$ FEC in the $1 \mathrm{M}$ LiDFOB ADN/DMC (1/1, wt./wt.) does not affect the conductivity. 
(a)

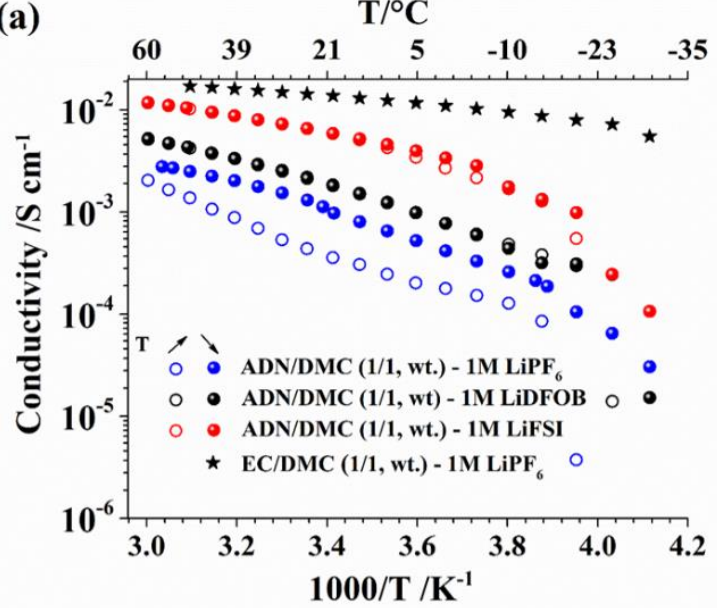

(c)
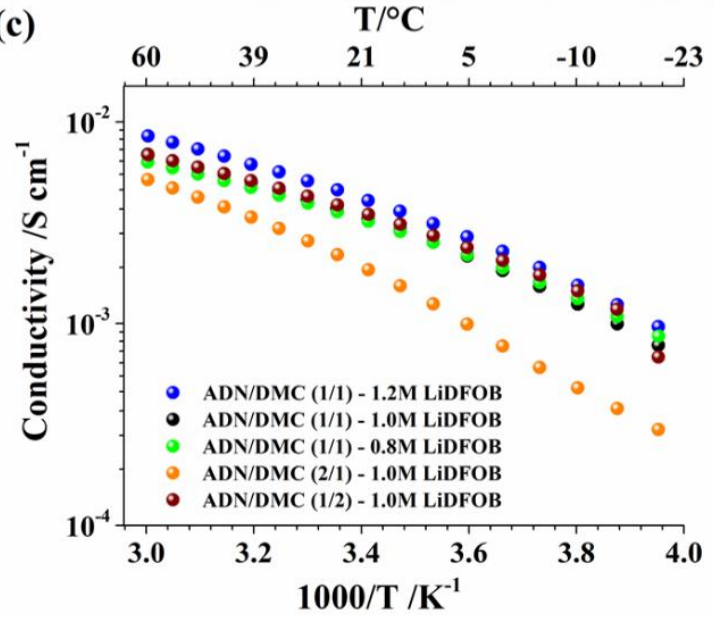

(b)

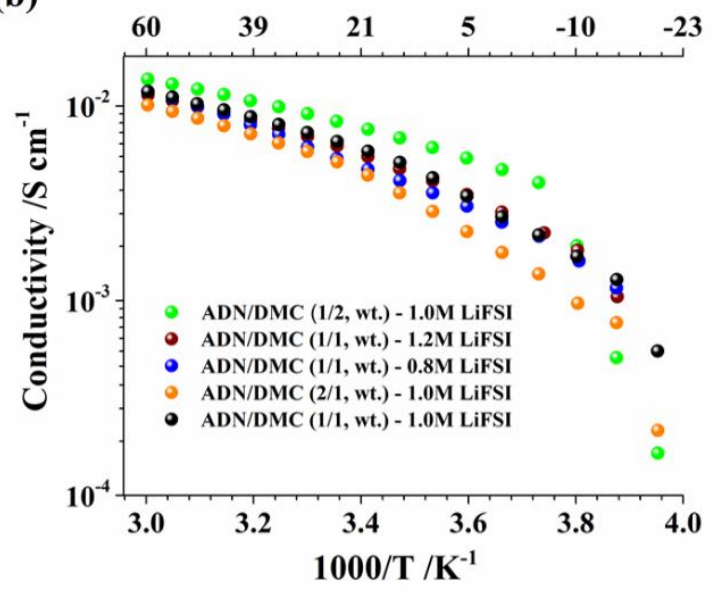

(d)

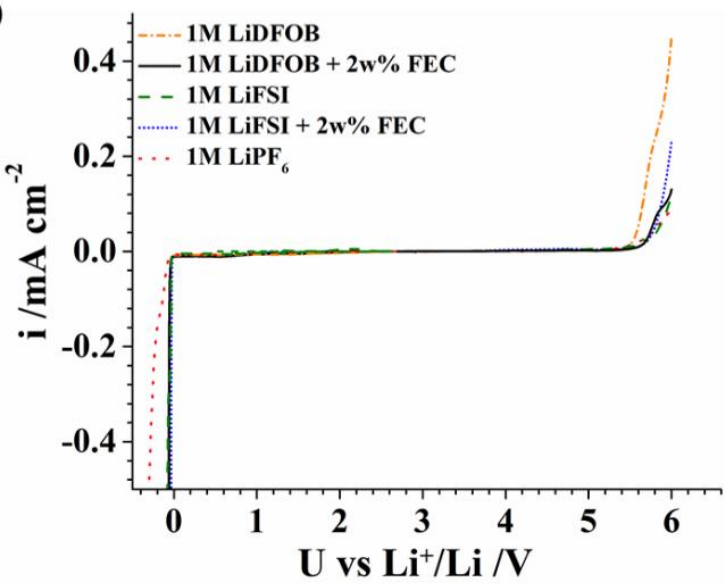

Figure 1: Conductivity plots of: (a) 1M ADN/DMC (1/1, wt./wt.) electrolytes; (b) ADN/DMC with various solvent ratios and LiDFOB concentrations; and (c) ADN/DMC with various solvent ratio and LiFSI concentrations; (d) Voltamperogram of 1M ADN/DMC (1/1, wt./wt.) electrolytes at $0.1 \mathrm{mV} \mathrm{s}^{-1}$ on $\mathrm{Pt}$ (oxidation) and $\mathrm{Ni}$ (reduction), $\mathrm{RE} \& \mathrm{CE}: \mathrm{Li}$.

The voltamperogramms of the 1M ADN/DMC 1/1 (wt./wt.) electrolytes are shown in Fig.1d. As can be seen, the electrochemical stability window (ESW) is rather large with $\mathrm{LiPF}_{6}, \mathrm{LiFSI}$ and $\mathrm{LiDFOB}$, and no extensive decomposition is detected before $5 \mathrm{~V}$. For the $\mathrm{LiPF}_{6}$ electrolyte, the exponential specific current increment [23], starts at $4.97 \mathrm{~V}$ vs. $\mathrm{Li}^{+} / \mathrm{Li}$, whereas for the LiFSI and LiDFOB electrolytes, the currents increase starts at $5.1 \mathrm{~V}$ and $5.05 \mathrm{~V}$ vs. $\mathrm{Li}^{+} / \mathrm{Li}$ respectively. On the cathodic scan, only low background currents between 7 and $11 \mu \mathrm{A} \mathrm{cm}^{-2}$ are observed before Li metal plating, possibly because of surface reaction (electrode passivation). 
It can be observed on the anodic side that the addition of FEC increases the anodic stability, to 5.22 V for the LiFSI electrolyte and $5.19 \mathrm{~V}$ for the LiDFOB electrolyte. The reason for this is not fully understood, however, in the case of mixed carbonate electrolytes (i.e. EC/DMC), it was shown that the structure of the double layer at the cathode during charge is enriched with the higher polarity component, which explains why the lower polarity solvent can be protected[24]. In the case of ADN/DMC/FEC mixture, $\mathrm{FEC}$ is by far the more polar molecule $\left(\varepsilon\left(\mathrm{FEC}, 60^{\circ} \mathrm{C}\right) \approx \varepsilon\left(\mathrm{EC}, 60^{\circ}\right)[25]\right)$ which could explain the higher stability of the electrolyte in presence of FEC. The LiFSI electrolyte exhibits the strongest background oxidation current which, however, stays below $6 \mu \mathrm{A} \mathrm{cm}^{-2}$ and is further reduced to $5 \mu \mathrm{A}$ $\mathrm{cm}^{-2}$ by the addition of $2 \mathrm{wt} . \%$ FEC.

\section{Graphite electrode cycling}

Li/graphite half-cells were assembled and tested in 1M LiDFOB and 1M LiFSI ADN/DMC electrolytes with and without the addition of $2 \mathrm{wt} . \%$ FEC as SEI forming additive. The cycling results are shown in Fig.2a and 2c. The efficiency of the first cycle for the LiDFOB electrolyte reaches $90.4 \%$ and is further increased to $92.2 \%$ by the addition of FEC. It is remarkably high considering the absence of EC as SEI forming co-solvent. The efficiencies then reach $99.7 \%$ and, for the FEC- containing electrolyte, above 99.9\%. The capacity retention at $\mathrm{C} / 2$ is rather high in both cases with an advantage for the FEC containing electrolyte. In addition, Fig. $2 \mathrm{~b}$ shows that the voltage profiles are more stable over cycling with FEC.

The substitution of LiDFOB by LiFSI results in lower cycled capacity and scattered efficiency, as seen in Fig.2c. Nevertheless, the first cycle efficiencies for 1M LiFSI and 1M LiFSI + 2wt.\% FEC are above $92 \%$ with only a small advantage for the FEC-containing electrolyte. More importantly, the cycled capacity is higher with FEC. The voltage profiles, in Fig.2d, show that the discharge (Li de-insertion) plateau at $\mathrm{C} / 2$ is shorter and shifted to higher potential without FEC. In both cases, however, only $c a$. $60 \mathrm{mAh} \mathrm{g}^{-1}$ capacity is charged galvanostatically, which show that the kinetics of $\mathrm{Li}^{+}$insertion are also relatively slow in both cases. 
(a)

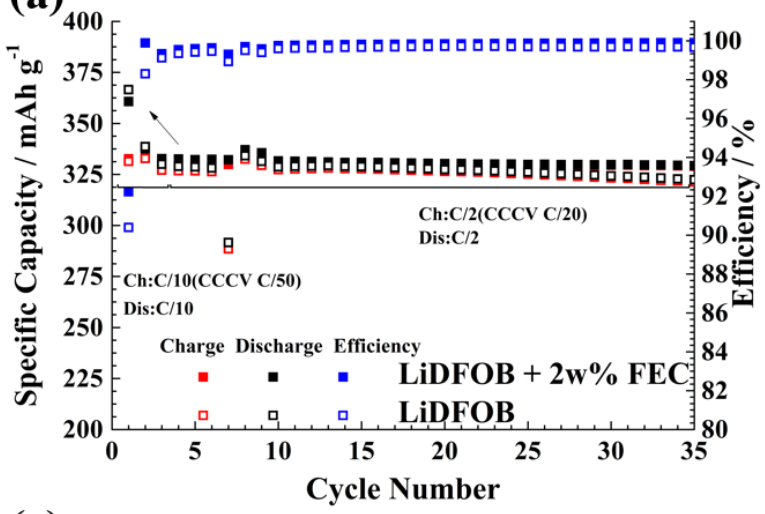

(c) Solid line 1M LiDFOB

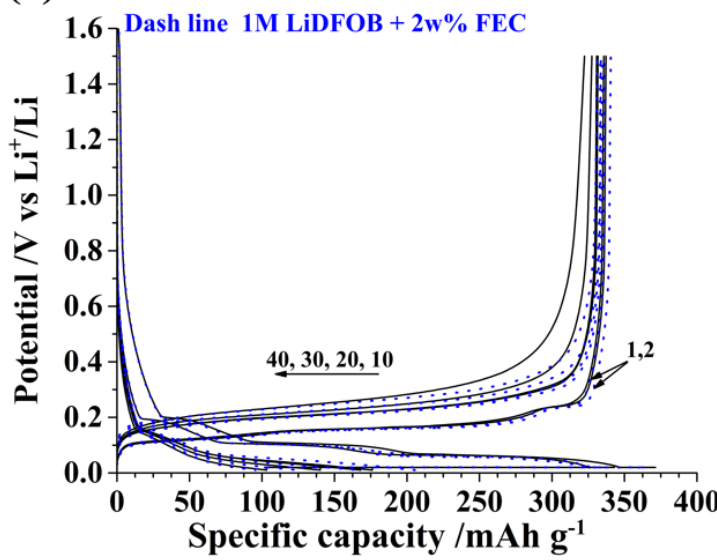

(b)

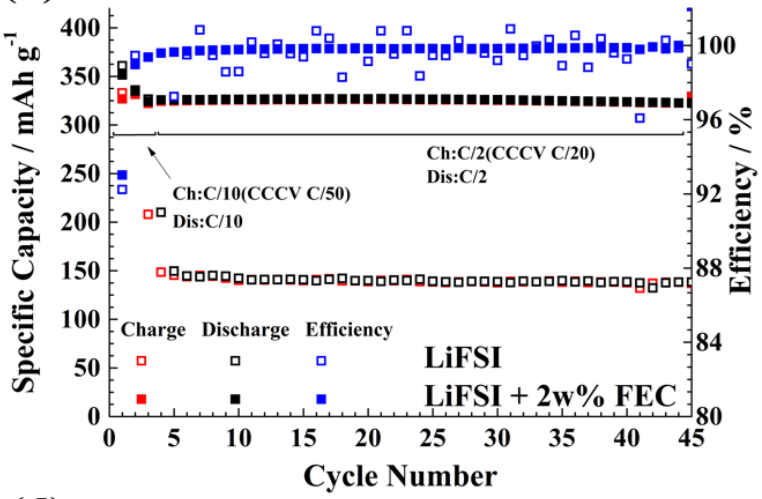

(d)

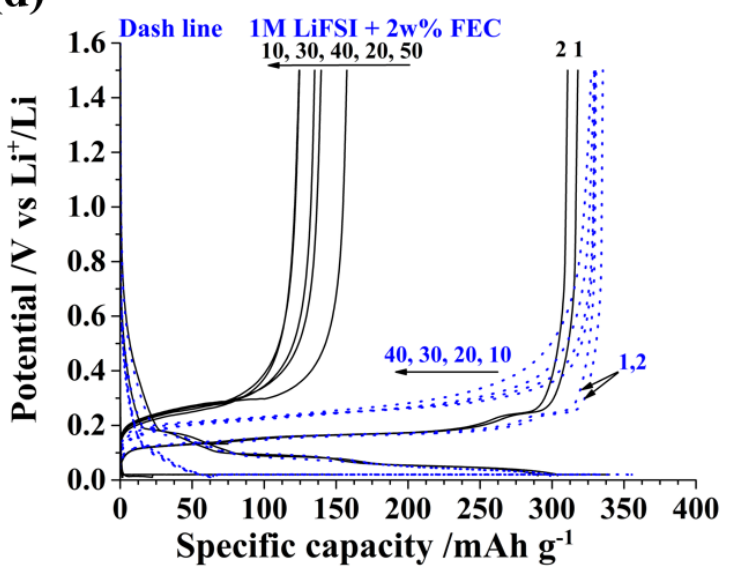

Figure 2. Graphite electrodes $7.5 \mathrm{mg} \mathrm{cm}{ }^{-2}$ cycled in 3 electrode cells in ADN/DMC (1/1, wt./wt.) with or without FEC with LiFSI and LiDFOB; (a) Comparison of cycling stability and efficiency of $1 \mathrm{M}$ LiFSI electrolytes; (b) Comparison of voltage profiles for selected cycles of $1 \mathrm{M}$ LiDFOB electrolyte $\left(1 \mathrm{C}=372 \mathrm{mAh} \mathrm{g}^{-1}\right) ;(\mathrm{c}) 1 \mathrm{M} \mathrm{LiFSI}$ comparison of cycling stability and efficiency; (d) $1 \mathrm{M} \mathrm{LiFSI}$ comparison of voltage profiles for selected cycles, cycle numbers are indicated next to the curves $(1 \mathrm{C}=$ $\left.372 \mathrm{mAh} \mathrm{g}^{-1}\right)$

\section{Graphite electrode rate capability}

The rate capability was investigated by applying varying specific currents (Fig.3). After a formation cycle at $\mathrm{C} / 10$, the cells were dis(-charged) at $\mathrm{C} / 10, \mathrm{C} / 5, \mathrm{C} / 2,2 \mathrm{C}, 5 \mathrm{C}, 10 \mathrm{C}, 20 \mathrm{C}$ for five cycles at each current and then back to $\mathrm{C} / 2$. The first cycle efficiencies are $93.46 \%$ and $91.87 \%$ for respectively, the LiFSI and the LiDFOB electrolytes, in agreement with the constant current cycling results. The cycled capacity, with $\mathrm{LiDFOB}$, is rather stable at each C-rate and the efficiencies are constantly above $99.8 \%$ from cycle $9^{\text {th }}$ (excepted at C-rate changes). On the other hand, the LiFSI electrolyte allows reaching 
$99.6 \%$ at cycle $7^{\text {th }}$ and $8^{\text {th }}(\mathrm{C} / 10$ and first cycle at $\mathrm{C} / 5)$, but the cell exhibits a more erratic behavior starting from the $9^{\text {th }}$ cycle, with much lower efficiencies.

When going back at $\mathrm{C} / 2$ after the rate test, the efficiencies of the LiDFOB cell reach $99.95 \%$ from the second cycle. If cycling also stabilizes with the LiFSI electrolyte, large irreversibilities are observed in this case until cycle 60. This is clearly due to more stable interfaces in LiDFOB cells. Indeed, it is known that LiDFOB allows, in some cases, graphite cycling in EC-free electrolyte [26], due to its own reduction, prior to other electrolyte components at ca. $1.8 \mathrm{~V}$ [21]. However, not all the irreversible capacity corresponds to lithium loss as efficiencies above $100 \%$ are recorded starting from $1 \mathrm{C}$ with the LiFSI electrolyte. As a matter of fact, if we plot the cumulative irreversible capacity of the LiFSI cell (Fig.3b), it can be seen that it increases significantly from $\mathrm{C} / 5$ to $\mathrm{C} / 2$, but then decreases at $1 \mathrm{C}$ and above, to reach the same value as for LiDFOB at the end of the C-rate test, at which point it starts increasing again. At $\mathrm{C} / 2$, during the $\mathrm{C}$-rate test, $\mathrm{Li}^{+}$mass transport probably limits the discharge (i.e. plating on $\mathrm{Li}$ metal and $\mathrm{Li}^{+}$and de-insertion from graphite), as some lithium remains trapped in the graphite electrode, which explains the efficiencies higher than $100 \%$ observed at higher rate, when graphite lithiation becomes more limiting.

In the voltage profiles, shown in Fig. $3 \mathrm{c}$ and d, it can be seen that the cycling stability at $\mathrm{C} / 10$ is lower with LiFSI and the capacity increases from cycle 1 to cycle 2 to reach the same value as for LiDFOB. The rate performance is then inferior at all C-rates and the ohmic drop increases significantly at $\mathrm{C} / 2$ (to the same level as $1 \mathrm{C}$ with the LiDFOB electrolyte) despite the higher conductivity of the electrolyte. 

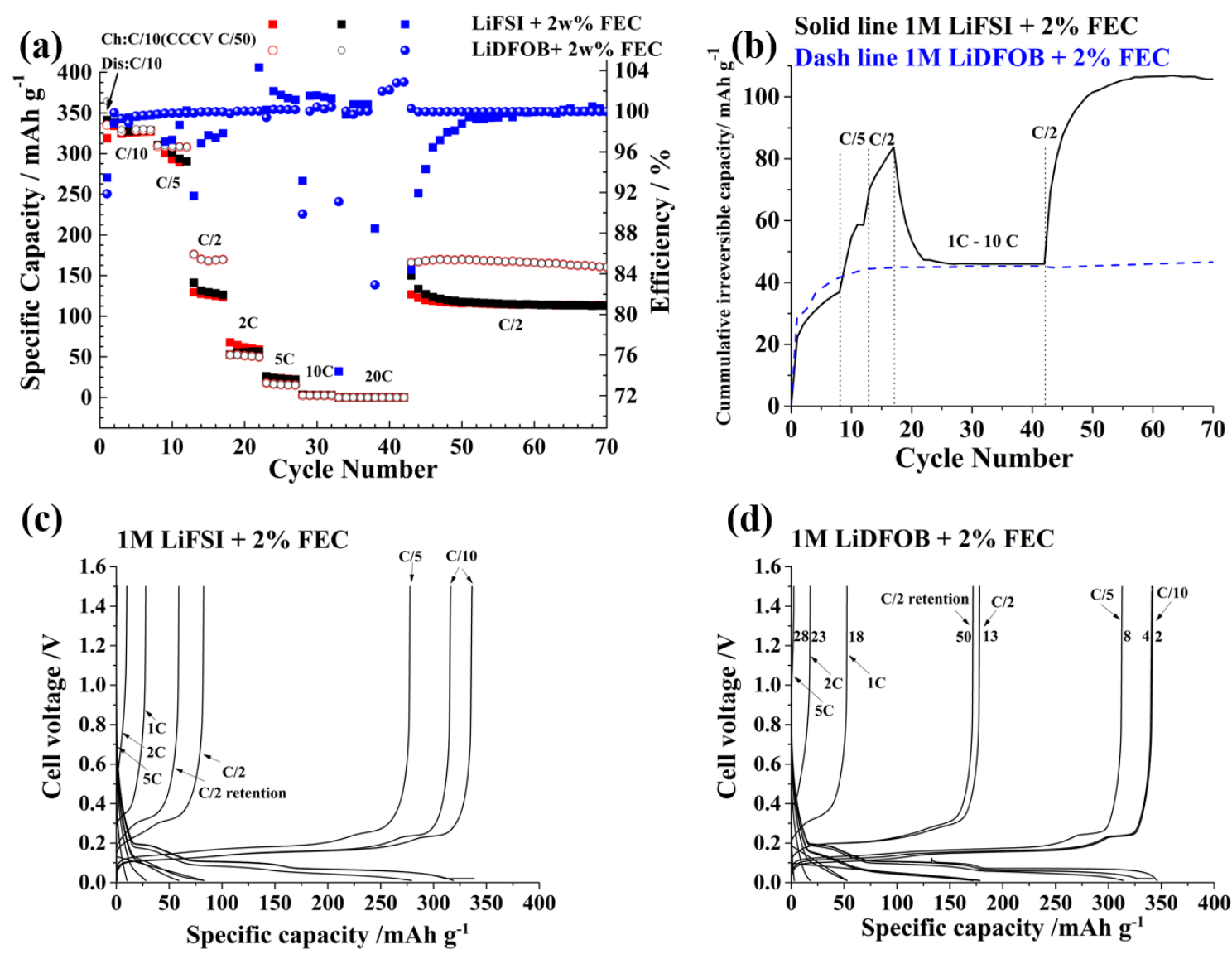

Figure 3. (a) Graphite electrodes $7.5 \mathrm{mg} \mathrm{cm}^{-2}$ cycled in 3 electrode cells in ADN/DMC (1/1, wt./wt.) with FEC in $1 \mathrm{M}$ LiDFOB and $1 \mathrm{M} \mathrm{LiFSI}$, comparison of rate capability and efficiency;(b) Comparison of cumulative irreversible capacity (c) and (d) Comparison of voltage profiles for selected cycles, cycle numbers are indicated next to the curves $\left(1 \mathrm{C}=372 \mathrm{mAh} \mathrm{g}^{-1}\right)$.

\section{Cycling of Graphite/ $\mathrm{LiFe}_{0.37} \mathrm{Mn}_{0.63} \mathrm{PO}_{4}$ (LFMP) up to $4.4 \mathrm{~V}$}

The capacities obtained at different discharge rates in graphite/LFMP full cells are shown in Fig.4a. At low discharge rates $(\mathrm{C} / 20)$, a capacity of $137 \mathrm{mAh} \mathrm{g}^{-1}$ is reached (i.e. the same as for a $1 \mathrm{M} \mathrm{LiPF}_{6}$ $\mathrm{EC} / \mathrm{DMC} / \mathrm{PC}+2 \% \mathrm{VC}$ electrolyte, data not shown). The discharge capacities diminished slightly for increasing discharge rates and led to the same capacity as the reference up to $1 \mathrm{C}$. As shown in the insert, when the current density increases, the plateau associated with the discharge process shifts to a lower 
potential because of the higher ohmic drop. The long term cycling test was conducted directly after the C-rate test. The results are shown in Fig.4b. The cells, charged and discharged with a C-rate of 1C, showed stable cycling behavior with a delivered capacity of $115 \mathrm{mAh} \mathrm{g}^{-1}$. After 50 cycles the capacity retention was $85 \%$ and the efficiency stayed above $98.8 \%$ from cycle 9 . The rate performance and the capacity cycled at $1 \mathrm{C}$ contrast with the half-cell results, which are probably influenced by a poor Li metal/electrolyte interface that limits the rate performance (the graphite electrodes being similar in mass loading).

\section{Cycling of $\mathrm{LiNi}_{0.33} \mathrm{Mn}_{0.33} \mathrm{Co}_{0.33} \mathrm{O}_{2}(\mathrm{NMC})$ up to $4.5 \mathrm{~V}$}

Recently, we reported the possibility of cycling Li/NMC cells up to $4.5 \mathrm{~V}$ in $1 \mathrm{M}$ LiDFOB ADN/DMC 1/1 (wt./wt.) + 2wt.\% FEC [27]. Herein Fig.5c. shows the cycling stability of a graphite/NMC cell made with commercial electrodes in 1M LiDFOB ADN/DMC 1/1 (wt./wt.) + 2wt.\% FEC. As can be seen, the obtained specific capacity in the first cycle is rather high with $189.4 \mathrm{mAh} \mathrm{g}^{-1}$ and a coulombic efficiency above $86 \%$. The efficiency then reaches above $99.2 \%$ from cycle 4 .

The corresponding voltage profiles are shown on Fig.5d and show that, at C/10, the discharge curves overlap well. However, at $1 \mathrm{C}$, it can be seen that, during charge, the voltage of the cell decreases at the beginning of the charge, which seems to indicate lithium plating occurs (which is coherent with the capacity delivered (as the NMC electrode capacity is $2.0 \mathrm{mAh} \mathrm{cm}^{-2}$ at $4.3 \mathrm{~V}$ and is cycled here up to 4.5 $\mathrm{V} \mathrm{vs} \mathrm{Li}^{+} / \mathrm{Li}$ ). Even in these conditions, the cell showed a capacity retention of $86 \%$ in the first 40 cycles. 


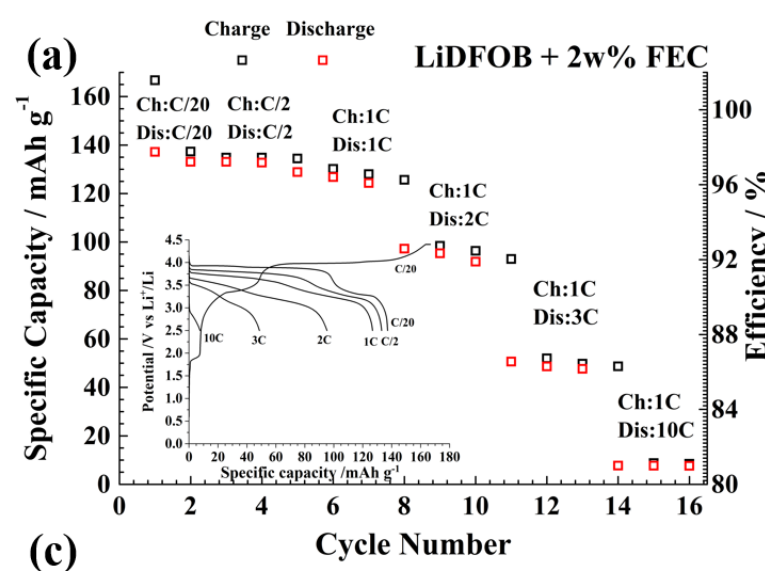

(c)

$$
\text { Cycle Number }
$$
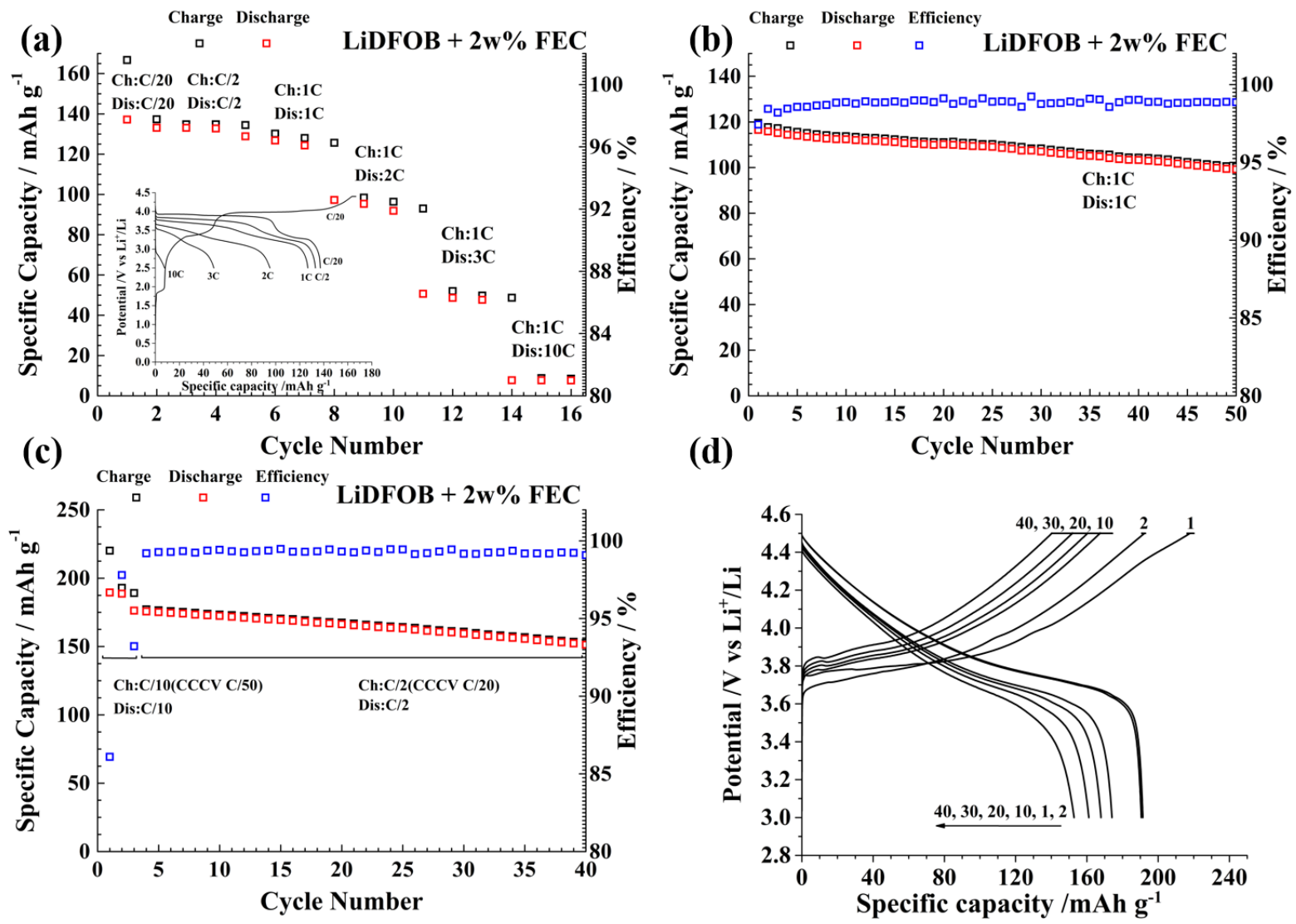

(d)

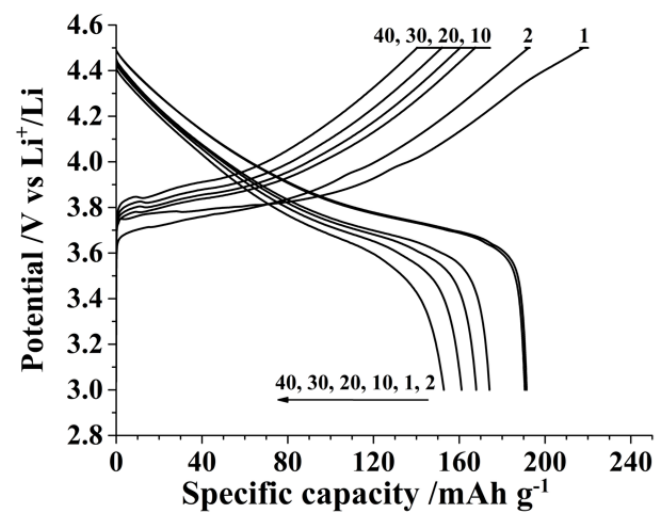

Figure 4. (a) C-rate capability of a graphite/LFMP full cell. (Insert): Voltage profile for various C-rates;

(b) Cycling stability of a graphite/LFMP full cell. Specific capacity refers to LFMP; (c) Cycling stability of a graphite/NMC full cell (NMC electrode cycled between $4.5 \mathrm{~V}$ vs $\mathrm{Li}^{+} / \mathrm{Li}$ and $3.0 \mathrm{~V}$ vs $\mathrm{Li}^{+} \mathrm{Li}$; (d) Potential profile of a NMC electrode at $\mathrm{C} / 10\left(1^{\text {st }}\right.$ and $2^{\text {nd }}$ cycle) and $\mathrm{C} / 2$ (following cycles). RE: Li, CE: Graphite. Specific capacity refers to NMC.

\section{Safety of electrolytes}

One of the critical characteristics of electrolytes for large scale LIB is safety and when the temperature of batteries increases, one of the first event able to trigger a thermal runaway is the evolution of the SEI and its reaction with lithiated graphite [28-30]. Thus, the safety of the electrolytes was determined via DSC on electrolyte in contact with charged graphite anodes, the corresponding DSC thermograms are shown in Fig.5. They show that FEC only has a weak influence on the SEI stability when LiDFOB is used as $\mathrm{Li}$ salt. In both cases, the exothermic reactions start around $150-160^{\circ} \mathrm{C}$ and increase progressively until reaching a maximum, which is also not influenced much. On the contrary, for the LiFSI based electrolyte, the effect of FEC is rather obvious, with a strong shift of the main peaks toward higher temperature with the addition of FEC. A closer look at the insert for the LiFSI $+2 \%$ electrolyte 
does show a limited reactivity starting at $150^{\circ} \mathrm{C}$ as well, but the main peak then starts at $c a .200^{\circ} \mathrm{C}$, whereas in the case of LiFSI without FEC, the decomposition start at $c a .180{ }^{\circ} \mathrm{C}$ and results in very sharp peak. If we compare with the exotherm onset temperature of $70^{\circ} \mathrm{C}$ published for $1 \mathrm{M} \mathrm{LiFSI}$ in EC/DMC (1/1, wt./wt.)[31], we can see that the SEI formed in the ADN/DMC electrolyte possesses a much higher stability.

The first exothermic onset for $1 \mathrm{M} \mathrm{LiPF}_{6}$ in $\mathrm{EC} / \mathrm{DMC} 1 / 1(\mathrm{LP} 30)$ is around $110{ }^{\circ} \mathrm{C}$, which indicates that, in ADN based electrolytes, the SEI is thermally more stable than in EC-based electrolytes. These results can be related to the thermal safety improvements observed, with the use of alkyl nitrile as additives, in EC-containing electrolytes for full graphite/ $\mathrm{LiCoO}_{2}$ cells $[13,14]$ and charged $\mathrm{LiCoO}_{2}$ cathodes [14]. Not only are these compound are efficient, at additive amounts, for stabilizing the electrolyte/cathode interface, but their effect on the SEI thermal stability at the anode is also positive (in absence of EC) and might possibly explain part of the graphite full cells improvements previously reported in EC-containing electrolytes. 


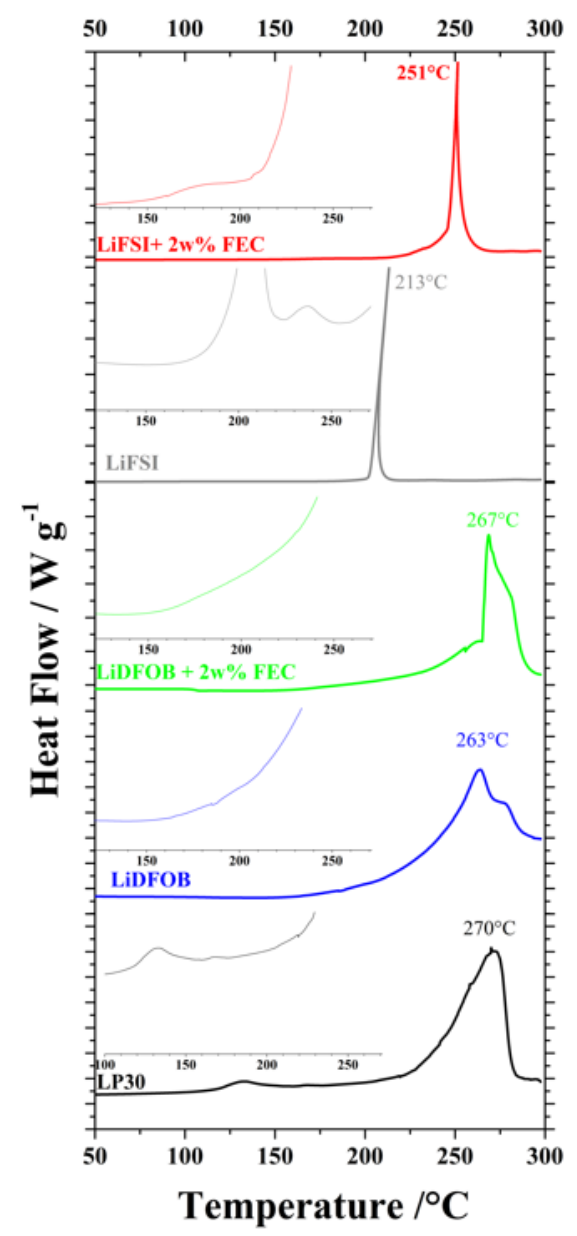

Figure 5. DSC thermogramms of $1 M A D N / D M C(1 / 1, w t . / w t$.$) electrolytes and LP30 as reference in$ contact with charged graphite electrodes.

\section{Conclusion}

EC-free Li-ion electrolytes based on ADN/DMC (1/1, wt./wt.) were prepared and tested for a use in Liion batteries. The conductivities of $1 \mathrm{M} \mathrm{LiFSI}$ and or $1 \mathrm{M}$ LiDFOB electrolytes are in the range of commercial Li-ion electrolytes for LiFSI and slightly lower for LiDFOB and both electrolytes exhibit wide ESW. The LiDFOB electrolyte allows graphite cycling with and without the addition of FEC as SEI forming additive and cycling efficiencies above $99.9 \%$ have been achieved with FEC as well as stable capacities. Graphite cycling with LiFSI electrolyte is greatly influenced by the presence of 
additive. The 1M LiDFOB ADN/DMC (1/1, wt./wt.) + 2wt.\% FEC electrolyte permits the cycling of graphite/LFMP cells at 4.4V with a discharge capacity of $137 \mathrm{mAh} \mathrm{g}^{-1}$ at low C-rates (C/20) and 115 $\mathrm{mAh} \mathrm{g}^{-1}$ up to $1 \mathrm{C}$. Moreover, the SEI formed in ADN/DMC electrolytes with LiFSI and LiDFOB are thermally more stable than state-of-the-art EC-based electrolytes.

\section{Acknowledgements}

The research presented is part of the 'SPICY' project funded by the European Union's Horizon 2020 research and innovation program under grant agreement $\mathrm{N}^{\circ} 653373$

\section{References}

[1] J. Xia, R. Petibon, D. Xiong, L. Ma, J.R. Dahn, Enabling linear alkyl carbonate electrolytes for high voltage Li-ion cells, J. Power Sources. 328 (2016) 124-135. doi:10.1016/j.jpowsour.2016.08.015.

[2] Q. Zhong, A. Bonakdarpour, M. Zhang, Y. Gao, J.R. Dahn, Synthesis and Electrochemistry of LiNi[sub x]Mn[sub 2-x]O[sub 4], J. Electrochem. Soc. 144 (1997) 205. doi:10.1149/1.1837386.

[3] A. Brenner, Note on an Organic-Electrolyte Cell with a High Voltage, J. Electrochem. Soc. 118 (1971) 461-462. doi:10.1149/1.2408081.

[4] J. Li, S. Jeong, R. Kloepsch, M. Winter, S. Passerini, Improved electrochemical performance of LiMO 2 ( M 1/4 Mn, Ni , Co ) e Li 2 MnO 3 cathode materials in ionic liquid-based electrolyte, J. Power Sources. 239 (2013) 490-495. doi:10.1016/j.jpowsour.2013.04.015.

[5] K. Xu, Electrolytes and Interphases in Li-Ion Batteries and Beyond, Chem. Rev. 114 (2014) 11503-11618. doi:10.1021/cr500003w.

[6] Y. Abu-Lebdeh, I. Davidson, High-Voltage Electrolytes Based on Adiponitrile for Li-Ion Batteries, J. Electrochem. Soc. 156 (2009) A60. doi:10.1149/1.3023084.

[7] H. Duncan, N. Salem, Y. Abu-Lebdeh, Electrolyte Formulations Based on Dinitrile Solvents for High Voltage Li-Ion Batteries, J. Electrochem. Soc. 160 (2013) A838-A848. doi:10.1149/2.088306jes. 
[8] C. Huntsman, JEFFSOL Alkylene Carbonates carbonate brochure, (2001).

http://www.huntsman.com/performance_products/Media

Library/global/files/jeffsol_alkylene_carbonates_brochure.pdf.

[9] E. Peled, The Electrochemical Behavior of Alkali and Alkaline Earth Metals in Nonaqueous Battery Systems_-The Solid Electrolyte Interphase Model, J. Electrochem. Soc. 126 (1979) 2047. doi:10.1149/1.2128859.

[10] J.R. Fong, R. von Sacken U. Dahn, Studies of Lithium Intercalation into Carbons Using Nonaqueous Electrochemical Cells, J. Electrochem. Soc. 137 (1990) 2009-2013. doi:10.1149/1.2086855.

[11] S. Tan, Y.J. Ji, Z.R. Zhang, Y. Yang, Recent Progress in Research on High-Voltage Electrolytes for Lithium-Ion Batteries, ChemPhysChem. 15 (2014) 1956-1969. doi:10.1002/cphc.201402175.

[12] Y. Ji, Z. Zhang, M. Gao, Y. Li, M.J. McDonald, Y. Yang, Electrochemical Behavior of Suberonitrile as a High-Potential Electrolyte Additive and Co-Solvent for Li[Li0.2Mn0.56Ni0.16Co0.08]O2 Cathode Material, J. Electrochem. Soc. 162 (2015) A774A780. doi:10.1149/2.1001504jes.

[13] Y.-S. Kim, T.-H. Kim, H. Lee, H.-K. Song, Electronegativity-induced enhancement of thermal stability by succinonitrile as an additive for Li ion batteries, Energy Environ. Sci. 4 (2011) 4038. doi:10.1039/c1ee01272j.

[14] Y.S. Kim, H. Lee, H.K. Song, Surface complex formation between aliphatic nitrile molecules and transition metal atoms for thermally stable lithium-ion batteries, ACS Appl. Mater. Interfaces. 6 (2014) 8913-8920. doi:10.1021/am501671p.

[15] A.J. Gmitter, I. Plitz, G.G. Amatucci, High Concentration Dinitrile, 3-Alkoxypropionitrile, and Linear Carbonate Electrolytes Enabled by Vinylene and Monofluoroethylene Carbonate Additives, J. Electrochem. Soc. 159 (2012) A370. doi:10.1149/2.016204jes.

[16] D. Aurbach, E. Zinigrad, Y. Cohen, H. Teller, A short review of failure mechanisms of lithium metal and lithiated graphite anodes in liquid electrolyte solutions, Solid State Ionics. 148 (2002) 405-416. doi:10.1016/S0167-2738(02)00080-2. 
[17] D. Farhat, F. Ghamouss, J. Maibach, K. Edström, D. Lemordant, Adiponitrile-Lithium Bis(trimethylsulfonyl)imide Solutions as Alkyl Carbonate-free Electrolytes for $\mathrm{Li}_{4} \mathrm{Ti}_{5} \mathrm{O}_{12}$ (LTO)/LiNi ${ }_{1 / 3} \mathrm{Co}_{1 / 3} \mathrm{Mn}_{1 / 3} \mathrm{O}_{2}$ (NMC) Li-Ion Batteries, ChemPhysChem. (2017). doi:10.1002/cphc.201700058.

[18] N. Nitta, F. Wu, J.T. Lee, G. Yushin, Li-ion battery materials: present and future, Mater. Today. 18 (2014) 252-264. doi:10.1016/j.mattod.2014.10.040.

[19] Z. Chen, Y. Qin, J. Liu, K. Amine, Lithium Difluoro ( oxalato ) borate as Additive to Improve the Thermal Stability of Lithiated Graphite, (2009) 69-72. doi:10.1149/1.3070581.

[20] M. Ishikawa, T. Sugimoto, M. Kikuta, E. Ishiko, M. Kono, Pure ionic liquid electrolytes compatible with a graphitized carbon negative electrode in rechargeable lithium-ion batteries, 162 (2006) 658-662. doi:10.1016/j.jpowsour.2006.02.077.

[21] M. Nie, B.L. Lucht, Role of Lithium Salt on Solid Electrolyte Interface (SEI) Formation and Structure in Lithium Ion Batteries, J. Electrochem. Soc. 161 (2014) A1001-A1006. doi:10.1149/2.054406jes.

[22] Y. Abu-Lebdeh, I. Davidson, New electrolytes based on glutaronitrile for high energy/power Li-ion batteries, J. Power Sources. 189 (2009) 576-579. doi:10.1016/j.jpowsour.2008.09.113.

[23] K. Xu, A. von Cresce, Interfacing electrolytes with electrodes in Li ion batteries, J. Mater. Chem. 21 (2011) 9849. doi:10.1039/c0jm04309e.

[24] J. Vatamanu, O. Borodin, G.D. Smith, Molecular Dynamics Simulation Studies of the Structure of a Mixed Carbonate/LiPF6 Electrolyte near Graphite Surface as a Function of Electrode Potential, J. Phys. Chem. C. 116 (2011) 1114-1121. doi:10.1021/jp2101539.

[25] M. Ohtake, K. Takimoto, N. Nanbu, M. Takehara, M. Ue, Y. Sasaki, Physical Properties of Fluorinated Cyclic Carbonates for Secondary Lithium Batteries, in: 2008. http://ma.ecsdl.org/content/MA2008-02/1/175.full.pdf.

[26] M.L. Lazar, B.L. Lucht, Carbonate Free Electrolyte for Lithium Ion Batteries Containing Butyrolactone and Methyl Butyrate, J. Electrochem. Soc. 162 (2015) A928-A934. doi:10.1149/2.0601506jes.

[27] E.C.S. Transactions, T.E. Society, Ethylene Carbonate-Free, Adiponitrile-Based Electrolytes 
Compatible with Graphite Anodes Niloofar Ehteshami, 77 (2017) 11-20.

[28] M.N. Richard, J.R. Dahn, Accelerating Rate Calorimetry Study on the Thermal Stability of Lithium Intercalated Graphite in Electrolyte. II. Modeling the Results and Predicting Differential Scanning Calorimeter Curves, J. Electrochem. Soc. 146 (1999) 2078. doi:10.1149/1.1391894.

[29] K. Edström, M. Herranen, Thermal Stability of the HOPG/Liquid Electrolyte Interphase Studied by In Situ Electrochemical Atomic Force Microscopy, J. Electrochem. Soc. 147 (2000) 3628. doi:10.1149/1.1393950.

[30] H. Yang, H. Bang, K. Amine, J. Prakash, Investigations of the Exothermic Reactions of Natural Graphite Anode for Li-Ion Batteries during Thermal Runaway, J. Electrochem. Soc. 152 (2005) A73. doi:10.1149/1.1836126.

[31] LiFSI vs. LiPF6 electrolytes in contact with lithiated graphite: Comparing thermal stabilities and identification of specific SEI-reinforcing additives, Electrochim. Acta. 102 (2013) 133141. doi:10.1016/J.ELECTACTA.2013.03.171. 